\title{
PENGETAHUAN MASYARAKAT PENGHUNI GUNUNG KEMUKUS TENTANG PENCEGAHAN HIV-AIDS DI KABUPATEN SRAGEN
}

\author{
Dwi Sulistyowati \\ Kementerian Kesehatan Politeknik Kesehatan Surakarta Jurusan Keperawatan
}

\begin{abstract}
Commercial Sex Workers, Knowledge, HIV-AIDS Prevention Efforts. The number of HIV-AIDS sufferers in Indonesia continues to increase and most productive attacking a young age. Health care workers interview results Hospital SoeratnoGemolong in October 2014, there were 25 HIV-positive AIDS, largely affected by HIV-AIDS is not a native districts miri Sragen. To analyze the mountain commercial sex workers kemukus knowledge about HIV-AIDS on HIV-AIDS prevention. The study design was observational analytic, using cross-sectional approach in which to make observations and measurements only once when the measurement variables were analyzed with the model Kai squared test (Chi Square) to analyze the relationship between one or more independent variables with the dependent variable category. The result of statistical test analysis Fisher's eact Testthe relationship between knowledge of HIV-AIDS prevention efforts gained value $P$ Value: 0.005> 0.001. HIV-AIDS prevention at the commercial sex workers in Mount Kemukus significant associated with HIV-AIDS knowledge
\end{abstract}

Keywords: Commercial Sex Workers, Knowledge, HIV-AIDS Prevention Efforts

\begin{abstract}
Abstrak: PSK, Pengetahuan, Upaya Pencegahan HIV-AIDS. Jumlah penderita HIVAIDS di Indonesia terus meningkat dan kebanyakan menyerang usia muda yang produktif. Hasil wawancara petugas kesehatan RSUD Soeratno Gemolong pada bulan oktober 2014, ada 25 penderita HIV-AIDS positif, sebagian besar yang terkena HIFAIDS adalah bukan penduduk asli wilayah kecamatan miri Kabupaten Sragen. Menganalisis pengetahuan PSK gunung kemukus tentang HIV-AIDS terhadap upaya pencegahan HIV-AIDS. Desain penelitian adalah analitik observasional, dengan menggunakan pendekatan cross-sectional di mana melakukan observasi dan pengukuran hanya sekali saat pengukuran variabel, dianalisis dengan model Uji Kai kuadrat (Chi Square) untuk menganalisis hubungan satu atau beberapa variabel independen dengan sebuah variabel dependen katagorik. Hasil analisis uji statistik Fisher's Eact Test hubungan antara Pengetahuan HIV-AIDS dengan upaya pencegahan diperoleh nilai P Value: $0.005>0,001$ maka dapat disimpulkan ada hubungan yang sangat signifikan antara pengetahuan HIV-AIDS dengan upaya pencegahan HIV-AIDS pada PSK di Gunung Kemukus.
\end{abstract}

Kata Kunci: PSK, Pengetahuan, Upaya Pencegahan HIV-AIDS. 


\section{PENDAHULUAN}

Pembangunan nasional menuju kearah pada terciptanya kualitas manusia yang diharapkan, maka diperlukan upaya penanggulangan HIV-AIDS secara sistematik melalui program yang didasarkan pada kajian ilmiah.

Jumlah penderita HIV-AIDS di Indonesia terus meningkat dan kebanyakan menyerang usia muda yang produktif. Laporan perkembangan HIVAIDS di Indonesia Triwulan III Tahun 2014. Situasi Masalah HIV-AIDS Triwulan II bulan Juli sampai bulan September Tahun 2014. HIV Dari bulan Juli sampai dengan September 2014 jumlah infeksi HIV yang baru dilaporkan sebanyak 7.335 kasus. Persentase infeksi HIV tertinggi dilaporkan pada kelompok umur 25-49 tahun $(69,1 \%)$, diikuti kelompok umur 20-24 tahun (17,2\%), dan kelompok umur $>=50$ tahun $(5,5 \%)$. Rasio HIV antara laki-laki dan perempuan adalah 1:1. Persentase faktor risiko HIV tertinggi adalah hubungan seks berisiko pada heteroseksual (57\%), LSL (Lelaki Seks Lelaki) (15\%), dan penggunaan jarum suntik tidak steril pada penasun (4\%). (Sistem Informasi HIV-AIDS \& IMS (SIHA, 2014)

AIDS Dari bulan Juli sampai dengan September 2014 jumlah AIDS yang dilaporkan baru sebanyak 176 orang. Persentase AIDS tertinggi pada kelompok umur 30-39 tahun (42\%), diikuti kelompok umur 20-29 tahun (36,9\%) dan kelompok umur 40-49 tahun $(13,1 \%)$. Rasio AIDS antara laki-laki dan perempuan adalah 2:1. Persentase faktor risiko AIDS tertinggi adalah hubungan seks berisiko pada heteroseksual (67\%), LSL (Lelaki Seks Lelaki) (6\%), penggunaan jarum suntik tidak steril pada penasun (6\%), dan dari ibu positif HIV ke anak $(4 \%)$.

Peneliti mewawancarai petugas kesehatan RSUD Soeratno Gemolong pada bulan oktober 2014, ada sekitar 25 penderita HIV-AIDS positif, sebagian besar bukan penduduk asli wilayah kecamatan miri Kabupaten Sragen. Dengan alasan tersebut penulis tertarik untuk meneliti lebih lanjut dengan judul “ Pengetahuan Masyarakat Penghuni Gunung Kemukus Tentang Pencegahan HIV-AIDS di Kecamatan Miri, Kabupaten Sragen ".

\section{METODE PENELITIAN}

Metode yang digunakan oleh peneliti didalam penelitian yang berjudul Hubungan antara pengetahuan dengan upaya pencegahan HIV-AIDS dianalisis dengan model Uji Kai kuadrat (Chi Square) untuk menganalisis hubungan satu atau beberapa variabel independen dengan sebuah variabel dependen katagorik.

$\mathrm{E}(\mathrm{Y} / \mathrm{X})=$ Antara 0 dan $1(0 \leq \mathrm{E}(\mathrm{Y} / \mathrm{X}) \leq 1)$

$\mathrm{Y}=$ Dependen (pengetahuan HIV-AIDS)

$\mathrm{X}=$ Independen (upaya pencegahan HIVAIDS)

\section{HASIL PENELITIAN}

Tabel 1

Karakteristik Responden berdasarkan Umur

\begin{tabular}{lll}
\hline Umur & Frequency & Persen $(\%)$ \\
\hline$<18$ tahun & 1 & 4.0 \\
26 tahun - & 13 & 52.0 \\
35 tahun & & \\
36 tahun - & 4 & 16.0 \\
45 tahun & & \\
46 tahun - & 7 & 28.0 \\
55 tahun & \\
\hline \multicolumn{2}{r}{ Total } & 25 \\
\hline \multicolumn{2}{r}{ Berdasarkan tabel di atas dari 25}
\end{tabular}

responden, usia 26-35 tahun sebanyak 13 
responden (52\%), usia 46-55 tahun sebanyak 7 responden (28\%), usia 36-45 tahun sebanyak 4 responden (16\%), usia < dari 8 tahun sebanyak 1 responden $(4 \%)$.

\section{Tabel 2}

Karakteristik Responden berdasarkan

\begin{tabular}{lll} 
& \multicolumn{2}{l}{ Pendidikan } \\
\hline Pendidikan & Frequency & Persen $(\%)$ \\
\hline SD & 20 & 80.0 \\
SLTP & 3 & 12.0 \\
SLTA & 2 & 8.0 \\
\hline Total & 25 & 1.00 \\
\hline
\end{tabular}

Berdasarkan data di atas dari 25 responden Pendidikan SD sebanyak 20 responden (80\%), Pendidikan SLTP sebanyak 3 responden (12\%), Pendidikan SLTP sebanyak 2 responden (8\%).

\section{Tabel 3}

Karakteristik Responden berdasarkan Pendidikan dan Upaya Pencegahan HIV-AIDS

\begin{tabular}{|c|c|c|c|c|c|c|c|c|}
\hline Upaya & Pen & lidikar & & & & & & \\
\hline $\begin{array}{l}\text { Penceg } \\
\text { ahan }\end{array}$ & $\begin{array}{l}S \\
D\end{array}$ & $\%$ & $\begin{array}{l}\mathrm{S} \\
\mathrm{L} \\
\mathrm{T} \\
\mathrm{P}\end{array}$ & $\%$ & $\begin{array}{l}\mathrm{S} \\
\mathrm{L} \\
\mathrm{T} \\
\mathrm{A}\end{array}$ & $\%$ & $\begin{array}{l}\mathrm{T} \\
\text { ot } \\
\text { al }\end{array}$ & $\%$ \\
\hline Baik & 13 & 76.5 & 3 & 17.6 & 1 & $\begin{array}{l}5 . \\
9\end{array}$ & 17 & 100 \\
\hline Cukup & 7 & 87.5 & 0 & 0 & 1 & $\begin{array}{l}12 \\
.5\end{array}$ & 8 & 100 \\
\hline Total & 20 & 80.0 & 3 & 12.0 & 2 & $\begin{array}{l}8 . \\
0\end{array}$ & 25 & 100 \\
\hline
\end{tabular}

Berdasarkan data di atas dari 25 responden pendidikan SD sebanyak 13 responden $(76,5 \%)$ upaya pencegahan tertular HIV-AIDS baik, pendidikan SLTP sebanyak 3 responden $(17,6 \%)$ upaya pencegahan tertular HIV-AIDS baik, pendidikan SLTA sebanyak 1 responden $(5,9 \%)$ upaya pencegahan tertular HIVAIDS baik. Sedangkan Dari 25 responden pendidikan SD sebanyak 7 responden $(87,5 \%)$ upaya pencegahan tertular HIVAIDS cukup, pendidikan SLTA sebanyak 1 responden $(12,5 \%)$ upaya pencegahan tertular HIV-AIDS cukup.
Tabel 4

Chi-Square Tests

\begin{tabular}{lccc}
\hline & Value & Df & $\begin{array}{c}\text { Asymp.Sig. (2- } \\
\text { sided) }\end{array}$ \\
\hline $\begin{array}{l}\text { Pearson Chi- } \\
\text { Square }\end{array}$ & $1,792^{\mathrm{a}}$ & 2 &, 408 \\
$\begin{array}{l}\text { Likelihood } \\
\text { Ratio } \\
\text { Linear-by- } \\
\text { linear } \\
\text { Association }\end{array}$ & 2,673 & 2 &, 263 \\
\hline $\begin{array}{l}\text { N of valid } \\
\text { cases }\end{array}$ &, 028 & 1 &, 867 \\
\hline \multicolumn{1}{c}{ Hasil analisis uji statistik Linear- }
\end{tabular}

by-linear Association hubungan antara Pendidikan HIV-AIDS dengan Upaya pencegahan diperoleh nilai $\mathrm{P}$ Value: 0.05 $>0,867$ maka dapat disimpulkan tidak ada hubungan antara pengetahuan dengan upaya pencegahan HIV-AIDS.

Tabel 5

Karakteristik Responden Berdasarkan Pengetahuan dengan Upaya Pencegahan HIV-AIDS

\begin{tabular}{lllllll}
\hline $\begin{array}{l}\text { Upaya } \\
\text { Penceg }\end{array}$ & \multicolumn{3}{c}{ Pengetahuan } & \multicolumn{5}{c}{ Total } & $\%$ \\
ahan & $\mathrm{k}$ & $\%$ & $\mathrm{C}$ & $\%$ & & \\
& \multicolumn{7}{c}{ uk } \\
up
\end{tabular}
responden upaya pencegahan baik sebanyak 17 responden (68\%) dengan pengetahuan pencegahan tertular HIVAIDS baik, Sedangkan upaya pencegahan cukup sebanyak 2 responden (25\%) dengan pengetahuan pencegahan tertular HIV-AIDS baik, upaya pencegahan cukup sebanyak 6 responden (75\%) dengan pengetahuan pencegahan tertular HIVAIDS cukup. 
Tabel 6

Chi-Square Tests

\begin{tabular}{|c|c|c|c|c|c|}
\hline & Value & $\mathrm{df}$ & $\begin{array}{l}\text { Asymp. } \\
\text { Sig. (2- } \\
\text { sided) }\end{array}$ & $\begin{array}{c}\text { Eact } \\
\text { Sig. } \\
(2- \\
\text { sided })\end{array}$ & $\begin{array}{l}\text { Exact } \\
\text { Sig. } \\
\text { (1.sid } \\
\text { ed) }\end{array}$ \\
\hline $\begin{array}{l}\text { Pearson } \\
\text { Chi- } \\
\text { Square }\end{array}$ & $16,776^{\mathrm{a}}$ & 1 & ,000 & & \\
\hline $\begin{array}{l}\text { Continuity } \\
\text { Correction } \\
\text { b }\end{array}$ & 12,816 & 1 & ,000 & & \\
\hline $\begin{array}{l}\text { Likelihoo } \\
\text { d Ratio }\end{array}$ & 18,557 & 1 & ,000 & & \\
\hline $\begin{array}{l}\text { Fisher's } \\
\text { Exact } \\
\text { Test }\end{array}$ & & & & ,000 & ,000 \\
\hline $\begin{array}{l}\text { Linear-by- } \\
\text { Linear } \\
\text { Associatio } \\
\mathrm{n}\end{array}$ & 16,105 & 1 & 000 & & \\
\hline $\begin{array}{l}\mathrm{N} \text { of Valid } \\
\text { Cases }\end{array}$ & 25 & & & & \\
\hline
\end{tabular}

Eact Test hubungan antara Pengetahuan HIV-AIDS dengan upaya pencegahan diperoleh nilai $\mathrm{P}$ Value: $0.05>0,001$ maka dapat disimpulkan ada hubungan yang sangat signifikan antara pengetahuan HIV-AIDS dengan upaya pencegahan HIV-AIDS pada PSK di Gunung Kemukus.

\section{PEMBAHASAN}

Dari 25 responden usia 26-35 tahun sebanyak 13 responden (52\%). Hasil analisis uji statistik chi square dan Linear-by-Linear Association hubungan antara Umur dengan upaya pencegahan HIV-AIDS diperoleh nilai P Value: $0.05>$ 0,015 maka dapat disimpulkan tidak ada hubungan antara umur dengan kejadian upaya pencegahan HIV-AIDS. Upaya penanggulangan HIV dan AIDS secara umum bertujuan memutus mata rantai penularan serta mengurangi dampak sosial dan ekonomi dari penyakit HIV-AIDS sehingga tidak menjadi masalah kesehatan bagi masyarakat (Nasronudin et all,.2007). Sedangkan secara khusus bertujuan untuk memberikan pelayanan dan perawatan yang holistic, komprehensif dan dukungan yang luas bagi ODHA dan keluarganya, disamping untuk memudahkan pasien ODHA dan keluarganya untuk memperoleh pelayanan dan perawatan serta mengurangi/ menyingkirkan stigma terhadap ODHA dan keluarganya (Nasronudin, Maramis M.M, 2007). 00 Persentase AIDS tertinggi pada kelompok umur 30-39 tahun (42\%), diikuti kelompok umur 20-29 tahun (36,9\%) dan kelompok umur 40-49 tahun $(13,1 \%)$ (SIHA, 2014).

Dari 25 responden pendidikan SD sebanyak 20 responden (80\%). Hasil analisis uji statistik chi square dan Linearby-linear Association hubungan antara Pendidikan HIV-AIDS dengan Upaya pencegahan diperoleh nilai $P$ Value: 0.05 $>0,867$ maka dapat disimpulkan tidak ada hubungan antara pengetahuan dengan upaya pencegahan HIV-AIDS. Hal ini sesuai dengan hasil penelitian Elanda Juwita, 2009 yang berjudul "Pekerja seks komersial yang berkeluarga" menunjukkan bahwa akibat pendidikan yang rendah setelah berkeluarga tidak mempunyai keahlian untuk mencari nafkah sehingga, pembagian peran dalam dirinya sebagai ibu dan PSK terpaksa dilakukan. Dua informan mengungkapkan dapat menjalankan peran ganda tersebut, sedangkan sisanya tidak dapat melakukannya secara sempurna. Dalam penelitian ini dapat disimpulkan bahwa peran ganda yang dijalankan PSK disebabkan oleh rendahnya pendidikan walaupun sudah berkeluarga dan memiliki anak, hal ini menyebabkan sebuah fungsi keluarga yang kurang sempurna akibat 


\begin{abstract}
pekerjaan tersebut. Upaya berdampak terhadap perkembangan sosial penanggulangan HIV-AIDS adalah dan ekonomi masyarakat, juga terjadi langkah usaha untuk menanggulangi reaksi di masyarakat. Penyebab utamanya penyebaran penyakit HIV-AIDS di masyarakat agar tidak menyebar luas dan mengalami peningkatan kwantitas dengan tetap mengacu pada prinsip-prinsip hak asasi manusia untuk menciptakan upaya

adalah pendidikan yang rendah, sosialisasi penyakit menular hubungan seks yang kurang, tanggung jawab pemerintah yang kurang serius untuk menangani masalah tersebut.
\end{abstract} penanggulangan yang inklusif, etis dan manusiawi, yaitu: menghilangkan stigma, diskriminasi dan hambatan-hambatan yang disebabkan oleh ketimpangan dan ketidaksetaraan jender pengembangan lingkungan, sistem dan kegiatan yang kondusif/ mendukung orang-orang maupun upaya penanggulangan secara hakiki (KPAN, 2011).

Hasil analisis uji statistik chi square dan Fisher's Eact Test hubungan antara Pengetahuan HIV-AIDS dengan upaya pencegahan diperoleh nilai $P$ Value: $0.05>0,001$ maka dapat disimpulkan ada hubungan yang sangat signifikan antara pengetahuan HIV-AIDS dengan upaya pencegahan HIV-AIDS. Hal ini sesuai dengan hasil penelitian (Syafrida Harahaf, 2013) yang berjudul "Faktor-faktor yang berhubungan dengan pekerja seks komersial tentang HIV-AIDS di kota Garut tahun 2008", Hasil uji statistik chi square dan fisher axact pada $\alpha=0,05$, yang artinya ada hubungan dengan pengetahuan PSK tentang HIV/AIDS. Hal ini sesuai dengan hasil penelitian (Astry Sandra Amalia, 2012) yang berjudul "Studi Dampak lokalisasi komplek pekerja seks komersial (PSK) terhadap masyarakat sekitar desa Purwajaya kabupaten Kutai Kartanegara“ diperoleh gambaran bahwa secara keseluruhan memang benar adanya dapak yang di timbulkan dari adanya lokalisasi komplek pekerja seks komersial (PSK) yaitu berupa penyebaran penyakit,

\section{KESIMPULAN DAN SARAN}

Umur PSK yang bekerja di gunung kemukus yang terbanyak adalah antara umur 26-35 tahun dari 25 responden sejumlah 13 responden (52\%). Pendidikan PSK yang bekerja di gunung kemukus yang terbanyak adalah pendidikan SD dari 25 responden sejumlah 20 responden (80\%). Pengetahuan PSK tentang HIVAIDS yang bekerja di gunung kemukus yang terbanyak adalah berpengetahuan baik 17 responden (68\%), dan yang berpengetahuan cukup 8 responden (33\%). Upaya pencegahan tertular HIVAIDS yang bekerja di gunung kemukus baik sejumlah 17 responden (68\%), dan yang berpengetahuan cukup 8 responden (33\%). Pengetahuan PSK tentang HIVAIDS terhadap upaya pencegahan HIVAIDS dari 25 responden upaya pencegahan baik sebanyak 17 responden (68\%) dengan pengetahuan pencegahan tertular HIV-AIDS baik, Sedangkan upaya pencegahan cukup sebanyak 2 responden $(25 \%)$ dengan pengetahuan pencegahan tertular HIV-AIDS baik, Dan upaya pencegahan cukup sebanyak 6 responden (75\%) dengan pengetahuan pencegahan tertular HIV-AIDS cukup. Wanita usia produktif perlu diperhatikan untuk menjaga organ reproduksi mereka, sehingga akan menghasilkan keturunan yang baik, seorang wanita produktif diberi ketrampilan agar mendapatkan penghasilan, karena faktor sosial ekonomi 
keluarga dan menjadi tulang punggung keluarga mereka mengambil resiko pekerjaan PSK. Pendidikan atau ilmu sangat penting untuk memberantas kebodohan atau ketidaktahuan, dengan pendidikan yang baik mereka bisa mencari pekerjaan dengan ilmunya, dan akan mendapatkan pekerjaan yang lebih baik.

Pengetahuan tentang HIV-AIDS sangat penting bagi masyarakat pada umumnya dan PSK pada khususnya, sehingga mensosialisasikan HIV-AIDS di tempat-tempat strategis seperti di sekolahsekolah, acara pertemuan resmi, dan tempat umum sangat penting untuk mencegah tertularnya HIV-AIDS.

Upaya pencegahan PSK terhadap tertularnya HIV-AIDS perlu ditingkatkan hasil penelitian $68 \%$ baik, sedangkan sisanya perlu diperhatikan karena dapat miningkatkan angka kejadian tertularnya HIV-AIDS.

Pengetahuan tentang HIV-AIDS sangat penting disosialisasikan pada masyarakat agar angka kejadian tertularnya HIV-AIDS di wilayah gunung kemukus tidak bertambah. Pemerintah wilayah yang berwenang perlu menangani merebaknya HIV-AIDS di wilayah gunung kemukus.

\section{DAFTAR RUJUKAN}

Rahayuningsih. 2008. Sikap. http:// nurulq.staff. gunadarma.ac.id/ downloads/ files/9095/ bab1-sikappdf. Diunduh tanggal 23 Maret 2014.

Suryana. 2009. Definisi Pengetahuan Serta faktor - faktor yang mempengaruhi pengetahuan. http: //duniabaca.com/definisipengetahuan-serta-faktor-faktor- yang-mempengaruhi-pengetahuan. Diunduh tanggal 12 Januari 2014.

Umeh CN, Essien EJ, Ezedinachi EN, Ross MW. 2008. Knowledge, beliefs and attitudes about HIV/AIDS related issues, and the sources of knowledge among health care professionals in Southern Nigeria. BioMed Central. http: //www. ncbi. nlm.nih. gov/pmc/ articles/ PMC2562902. Diunduh tanggal 8 Maret 2014.

UNAIDS. 2011. Global summary of the AIDS epidemic 2010. http://www.who.int/ hiv/data/ 2011_epi_core_en.png. Diunduh 2 Mei 2014. 